\title{
Rancang Bangun Tracking Mobil Patroli Berbasis Teknologi GPS Dan SMS Gateway
}

\author{
Bambang Wahyudi ${ }^{1}$, I Made Sukarsa ${ }^{2}$, Putu Wira Buana ${ }^{3}$ \\ Jurusan Teknik Elektro, Fakultas Teknik, Universitas Udayana Denpasar - Bali \\ Email :wahyudi.b@yahoo.com ${ }^{1}$, e_arsa@yahoo.com ${ }^{2}$,wbhuana@gmail.com ${ }^{3}$
}

\begin{abstract}
Abstrak
Perkembangan teknologi informasi yang semakin maju, banyak orang yang membutuhkan informasi yang cepat dan akurat. Makalah ini dibuat bermaksud menghasilkan sebuah sistem informasi yang digunakan untuk memantau posisi dari mobil patroli. Memanfaatkan teknologi GPS dan SMS gateway tracking mobil patroli dapat ditampilkan di Web untuk posisi atau koordinat dari tiap-tiap mobil patroli. Bahasa pemrograman yang digunakan adalah PHP dan database MySQL. Hasil dari rancangan sistem ini adalah sistem informasi tracking mobil patroli yang meliputi pengolahan data GPS, mobil patroli, posisi realtime dan histori dari mobil patroli.
\end{abstract}

Kata kunci: GPS, SMS Gateway, Web, PHP, MySQL

\begin{abstract}
The advance development of information technology, many people need the information quickly and accurately. This papers is made intends to produce an information system used to monitor the position of a patrol car.Utilizing GPS technology and SMS gateway patrol car tracking can be displayed on the Web for a position or coordinates of each patrol car. The programming language used is PHP and the MySQL database. The result of this design system is information system the patrol car that includes tracking GPS data processing, patrol cars, the real-time and historical position of the patrol car.
\end{abstract}

Keywords: GPS, SMS Gateway, Web, PHP, MySQL

\section{PENDAHULUAN}

Perkembangan teknologi yang pesat, mendorong manusia untuk melakukan suatu percobaan, guna mengembangkan dan menemukan hal yang terbaru dalam dunia teknologi informasi. Cara-cara yang baru dikaji dan dicoba guna memberikan manfaat, juga mempermudah berbagai aktifitas. Perkembangan teknologi yang sangat cepat, dalam dunia teknologi informasi menimbulkan banyak persaingan berbagai perusahaan dalam mendapatkan keuntungan besar dari konsumen.

Keperluan akan pemantauan koordinat dari kendaraan sudah menjadi kebutuhan, dan dapat dilihat semakin banyak teknologi ini digunakan. Seperti pemantauan mobil dinas dan alat tranportasi lainnya, baik tranportasi untuk barang dan manusia. Saat ini teknologi yang digunakan teknologi suara dengan handy talky, juga melalui komunikasi data yang menggunakan radio trunking. Juga sudah dilengkapi dengan pemasangan Global Positioning System (GPS). Efektifitas cara ini masih kurang, disebabkan oleh jangkauan yang kurang luas. Teknologi penentuan koordinat seperti GPS sudah berkembang dengan akurasi yang lebih akurat. Koordinat dapat diketahui jika transportasi tersebut sudah terpasang GPS receiver, untuk menerima koordinat dari satelit GPS.[1]

Pemetaan teknologi GPS ini, untuk fasilitasnya sudah tersedia di Google Maps, Google Earth dan GPS (Global Positioning System). Fasilitas ini dapat digunalan untuk mengetahui koordinat suatu lokasi. Jaringan teknologi (wireless) yang sudah berkembang, terutama pada handphone. Handphone saat ini sudah tersedia fasilitas 
GPRS (General Packet Radio Service), dapat digunakan untuk mengirim data tanpa kabel melalui internet. [2]

\section{TINJAUAN PUSTAKA 2.1 Global Positioning System (GPS)}

Global Positioning System (GPS) merupakan sistem navigasi satelit, dengan 24 satelit yang beroperasi serta 3 satelit cadangan. Jarak orbit satelit tersebut $20.200 \mathrm{~km}$ dengan waktu orbit 12 jam, yang memancarkan sinyal berita gelombang radio. Sistem GPS ini, dioperasikan dan diatur konfigurasinya oleh Departemen Pertahanan AS. Sebanyak 4 sampai 10 satelit untuk melayani setiap tempat di muka bumi. Empat buah jam atom dipasang pada tiap satelit untuk mengatur waktu dengan akurasi spermiliar detik. Akurasi teknologi GPS kurang lebih 1 meter untuk penentuan koordinat lokasi. [2]

\subsection{SMS}

Short Message Service (SMS) merupakan tipe Instant Messaging, sifat dari pengiriman paket SMS ini out of band yang menggunakan bandwith yang rendah. Apabila terjadi kegagalan pengiriman pesan dapat disimpan dlam jaringannya. Penghantar SMS ini pada channel signal GSM (Global System for Mobile) dengan spesifikasi ETSI. Juga dapat digunakan pada teknologi GPRS dan CDMA.[3]

\subsection{SMS Gateway}

SMS Gateway adalah pintu gerbang untuk pengiriman informasi berupa SMS. Secara otomatis pesan dapat dikirim ke ratusan nomor dan cepat yang langsung terhubung dengan database nomor-nomor ponsel saja tanpa mengetik ke setiap nomor karena semua nomor akan diambil secara otomatis dari database tersebut.[4]

\subsection{GAMMU}

Gammu merupakan tool untuk pengembangan aplikasi SMS Gateway, sebagai komponen utama. Komponen ini menghantarkan data-data SMS dari handphone ke komputer begitu juga sebaliknya. Keunggulan Gammu sebagai tool untuk SMS Gateway, sebagai berikut :

1. Dapat beroperasi pada Windows dan Linux.

2. Gammu kompatible dengan banyak device dan ponsel.

3. Database Gammu adalah MySQL, dapat digunakan pada aplikasi desktop dan interface web-based.

4. Gammu dengan efisien membantu menggunakan fitur-fitur yang ada pada ponsel.

5. Gammu kompatible dengan kabel USB dan SERIAL.[5]

\subsection{PHP}

PHP (akronim dari PHP Hypertex Processor) merupakan bahasa pemrograman yang mempunyai kemampuan memproses data berbasis web. PHP sebagai server-side embedded script language dengan sintak dan perintah yang dijalankan oleh server pada halaman HTML. Hasil dari aplikasi yang dibangun dengan PHP dapat dijalankan pada web browser, dengan semua proses berjalan di server. Server akan bekerja apabila ada permintaan dari klien.[6]

\subsection{XAMPP}

XAMPP berfungsi sebagai server berdiri sendiri (localhost) untuk membangun aplikasi berbasis web. Pada XAMPP terdapat program http server, MySQL database serta Apache. Bahasa pemrograman PHP dan Perl yang digunakan sebagai penterjemah bahasa.[7]

\subsection{MySQL}

MySQL adalah piranti lunak gratis dibawah lisensi GNU General Public Licensi (GPL), juga dijual lisensi yang komersial untuk penggunaan yang tidak kompatibel dengan GPL. MySQL menggunakan sistem manajemen basis data SQL atau DBMS, yang sudah diinstalasi di seluruh dunia sekitar 6 juta.[8]

\subsection{Google Maps}

Google Maps merupakan peta glove virtual gratis yang dudah disediakan oleh Google secara online, selain google 
menawarkan peta yang dapat diseret dari gambar satelit. Juga menawarkan perencanaan rute untuk pencarian letak bisnis di dunia (hanya pusat kota). Saat ini Google Maps yang tersedia masih versi beta.[9]

\subsection{Google Maps API}

Google Maps API sudah sering digunakan untuk menciptakan berbagai aplikasi, karena dapat digunakan dalam bahasa pemrograman PHP, perl, cgi dan lainnya. Aplikasi yang dihasilkan dari google maps ini diharapkan opensource, karena bahasa pemrograman Google Maps API adalah opensource.[10]

\section{HASIL DAN PEMBAHASAN}

\subsection{Identifikasi Kebutuhan Hardware Dan Software}

Perangkat keras yang digunakan untuk pembuatan atau implementasi dari aplikasi ini adalah satu unit laptop, modem, simcard GSM, telepon selular dan GPS. Untuk lebih detailnya spesifikasinya seperti berikut ini : Hardware
a. Processor Intel Core i3 $2.30 \mathrm{Ghz}$
b. RAM DDR3 2 GB
c. Hardisk $300 \mathrm{~GB}$
d. Modem ASUS FONEPAD 7
e. Simcard
f. GPS
g. Telepon selular Sony Ericsson K700i

Software

1. Sistem Operasi Windows menggunakan Windows 7

2. Web Browser

Web browser digunakan untuk eksekusi dari aplikasi tersebut, misal Google Chrom

3. XAMPP

Software portable ini berisi bahasa pemrograman PHP versi 5.5.28 dengan database server MySQL versi 5.6.26, apache versi 2.4.16 sebagai web server, dan database manager phpMyAdmin versi 4.4.14.

\subsection{Hasil Rancangan Database}

Perancangan database ini menampilkan rangkaian database yang dibutuhkan untuk merancang aplikasi pemantauan posisi mobil patroli polisi berbasis GPS yang akan dibangun, berikut tabel perancangan database untuk aplikasi pemantauan posisi mobil patroli berbasis
GPS yang akan dibangun. Dapat dilihat pada Tabel 1.

Tabel 1 Tabel Database

\begin{tabular}{|l|l|}
\hline Jenis & Deskripsi \\
\hline Armada & $\begin{array}{l}\text { Tabel ini berisi data-data } \\
\text { armada yang sudah } \\
\text { didaftarkan ke dalam } \\
\text { database aplikasi }\end{array}$ \\
\hline Log_tbl & $\begin{array}{l}\text { Tabel ini berisi data-data log } \\
\text { dari aktifitas yang terajdi di } \\
\text { dalam aplikasi }\end{array}$ \\
\hline $\begin{array}{l}\text { Pending_u } \\
\text { ser }\end{array}$ & $\begin{array}{l}\text { Tabel ini berisi data-data user } \\
\text { yang aktivasi masih tertunda } \\
\text { atau belum aktivasi lewat link } \\
\text { yang sudah terkirim lewat } \\
\text { email }\end{array}$ \\
\hline Tracking & $\begin{array}{l}\text { Tabel ini berisi data-data } \\
\text { interval waktu pengiriman } \\
\text { sinyal/posisi mobil patroli }\end{array}$ \\
\hline
\end{tabular}

\subsection{Tampilan Halaman Awal Aplikasi}

Tampilan halaman awal ini terdiri dari nama aplikasi dan halaman login dari aplikasi.Sebelum menggunakan aplikasi ini, pengguna harus melakukan login ke dalam aplikasi dengan mengunakan user yang sudah terdaftar dalam database apliksi tracking. Dapat dilihat pada Gambar 1.

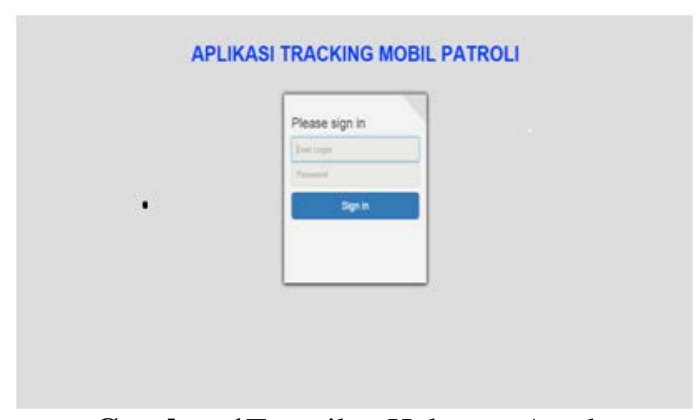

Gambar 1Tampilan Halaman Awal

\subsection{Tampilan Halaman Utama}

Tampilan halaman utama ini terdiri dari menu Dashboard, Armada, Tracking History, User, Log Files dan Peta. Tampilan halaman utama juga terdapat tampilan posisi real time dari mobil patroli, yang dapat digunakan memantau posisi dari mobil patroli oleh user. Dapat dilihat pada Gambar 2. 


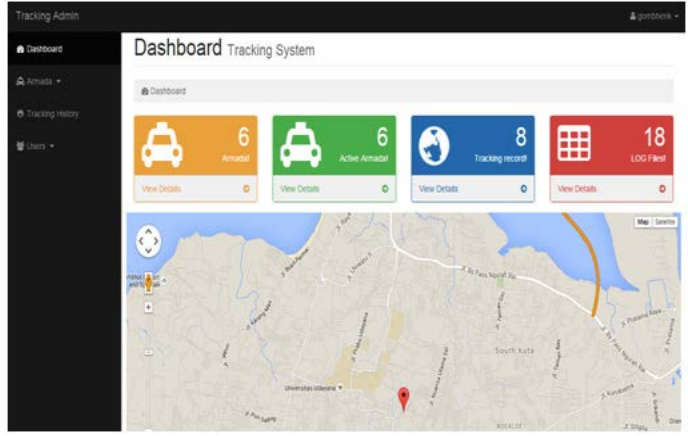

Gambar 2 Tampilan halaman utama

\subsection{Tampilan Halaman Hasil TrackingHistory}

Tampilan halaman hasil tracking history menampilkan hasil dari tracking histori mobil patroli. Hasil dapat dilihat pada tampilan gambar dibawah, berupa titik koordinat awal dan akhir dari mobil patroli. Dapat dilihat pada Gambar 3.
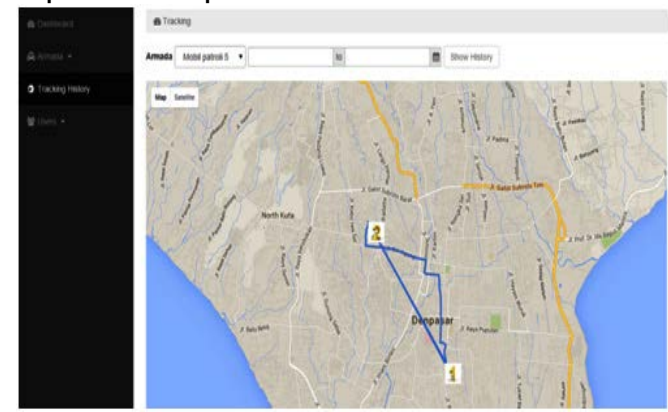

Gambar 3 Tampilan Halaman Hasil Tracking History

\subsection{Analisa Kegagalan}

\subsubsection{Kendala}

Kendala yang timbul dari pembuatan aplikasi sistem tracking mobil patroli ini, antara lain :

- Spesifikasi dari handphone yang sesuai atau cocok dengan gammu. Untuk hal tersebut dapat dilihat pada gammu phone database [http://wammu.eu/phones/].

- Membutuhkan spesifikasi GPS yang lebih tinggi untuk mendapatkan proses penerimaan signal dan posisi koordinat yang lebih baik.

\subsubsection{Kejadian yang Menyebabkan Sistem Tracking Mobil Patroli Gagal}

Kejadian yang bisa menyebabkan sitem tarcking mobil patrol gagal, antara lain :

- Tidak terkirim atau menerima sms dari server sistem aplikasi atau GPS sehingga menyebabkan gagalnya sistem aplikasi ini dalam informasi update terbaru posisi dari mobil patroli.

- Tidak menerima sinyal dari BTS Selular terdekat sehingga menyebabkan GPS tidak dapat mengirim dan menerima SMS koordinat dari GPS.

- Tidak menerima sinyal dari satelit sehingga menyebabkan GPS tidak bisa mengirimkan koordinat dengan tepat dari posisi terakhir mobil patroli.

\section{METODE PENELITIAN}

Pembuatan aplikasi sistem ini dengan menggunakan GPS mobile untuk kendaraan yang berisikan simcard, dimana dari GPS mobile ini akan mengirimkan data berupa koordinat setiap waktu interval yang sudah ditentukan. Setelah dikirim sms dari server terlebih dahulu melalui sms gateway yang dibuat. Data tersebut akan diterima oleh server, dimana server juga menggunakan simcard yang sudah terpasang pada handphone yang terhubung dengan server. Sebelum tersimpan dalam database data tersebut akan diterima oleh Gammu, kemudian akan diteruskan ke database yang sudah tersedia didalam server aplikasi tracking ini.

Untuk merancang, membangun dan memanfaatkan aplikasi/sistem ini mebutuhkan beberapa perangkat keras, antara lain:

- GPS tracker

Alat pengirim sinyal ini posisi mobil patroli polisi. GPS tracker harus selalu dalam keadaan aktif/hidup. Apabila GPS tracker dalam kondisi tidak aktif/off, maka GPS tracker tidak bisa mengirimkan koordinat dari posisi mobil patroli, menyebabkan posisi mobil patroli tidak bisa terpantau.

- GSM Modem

Alat ini berfungsi menerima data koordinat yang dikirim GPS tracker. Alat ini yang juga mengirim data ke server melalui kabel penghubung.

- Komputer Server

Perangkat keras yang berfungsi sebagai server adalah perangkat keras yang dipakai untuk merancang dan membangun aplikasi ini serta dimanfaatkan sebagai server untuk aplikasi ini. Perangkat keras ini berupa PC (Personal Computer) 
- Komputer Client

Perangkat keras yang digunakan sebagai client adalah perangkat keras yang digunakan oleh pengguna berupa PC, laptop, handphone juga alat elektronik lainnya yang sudah dilengkapi web browser dan terkoneksi dengan internet agar dapat digunakan mengakses aplikasi ini via web setiap saat selama GPS tracker yang diletakkan pada mobil patroli polisi dalam keadaan aktif/on.

\section{KESIMPULAN}

Dari hasil analisis dan perancangan aplikasi, serta hasil dan pembahasan dapat diambil kesimpulan sebagai berikut :

1. Hasil dari penelitian ini berupa aplikasi Rancang Bangun Tracking Mobil Patroli Berbasis Teknologi GPS dan SMS Gateway.

2. Rancang Bangun Tracking Mobil Patroli ini berisi aplikasi pengolahan data dari mobil patroli yang berupa koordinat.

3. Fitur utama dari aplikasi, yaitu fitur histori tracking. Dapat menampilkan hasil histori perjalanan dari periode yang telah diinputkan dan menampilkannya dengan baik.

4. Performa dari GPS juga kurang bagus dalam mengirimkan datanya, karena pada waktu tertentu GPS tidak dapat mengirimkan datanya dengan tepat disebabkan GPS tidak menerima signal dari satelit.

5. Kinerja dari aplikasi sangat dipengaruhi oleh koneksi internet, terutama dari GPS tracker ke HP. Dari HP ke database kemudian diolah datanya oleh aplikasi dan ditampilkan pada user maupun dari aplikasi web ke web browser yang digunakan oleh user. Dengan kecepatan internet yang bagus, maka akan semakin bagus dalam proses pelacakkan. Karena data atau koordinat yang ditampilkan di peta dan perpindahan posisi pada peta mengikuti marker dari mobil patroli pada Google Map juga menggunakan resource internet yang cukup besar dan berkesinambungan.

6. DAFTAR PUSTAKA

[1] Muchlas, 2006. Sistem Kendali Peralatan Rumah Tangga Berbasis HT Dan Mikrokontroler AT89S51 Volume 4, No. 1
[2] Ronald Rusli,2013.Membuat Aplikasi GPSdan Suara Antrian dengan PHP

[3] Yudi Wiharto, 2011. Sistem Akademik Berbasis Teknologi SMS Gateway. Jurnnal Teknologi dan Informatika Volume 1, No.1.

[4] Pandapotan Siagian,2014.Sistem Informasi Penerimaan Mahasiswa dengan SMS Gateway. Jurnal SistemInformatika, Volume 6, No. 1.

[5] Thoyib, 2010. Pelayanan Pelanggan Berbasis SMS Gateway. Jurnal UMB/Aplikasi SMS Gateway

[6] Wahana Komputer, 2012. Membangun Web Interaktifdengan Adobe Dreamweaver CS5.5, PHP dan MySQL.

[7] Madcoms Madiun,2014.Pemrograman PHP dan MySQL untukPemula

[8] Madcoms Madiun, 2009.Menguasai XHTML, CSS, PHP dan MySQL melalui Dreamweaver.

[9] https://maps.google.com

[10] https://developers.google.com/maps/ documentation/javascript/ 